Оригинальная статья/Original article

УДК 334.5.7

DOI: http://doi.org/10.20914/2310-1202-2017-2-225-230

Механизм развития интеграционных процессов в регионе

\begin{tabular}{lll}
\hline \hline Василий М. Баутин & 1 & BMB@mail.ru \\
Марина В. Филатова & 1 & fltvmrn@rambler.ru \\
Камара Абубакар & 1 & aboubacar2017camara@gmail.com \\
Омесу Экеледиричукву Крис & 1 & ekeleliveinrussia@yahoo.com \\
\hline
\end{tabular}

1 Воронежский государственный университет инженерных технологий, пр-т Революции, 19, г. Воронеж, 394066, Россия

Реферат. В условиях ослабления экономического развития региона, необходимо найти новые пути для повышения эффективности взаимодействия экономических структур региона. Одним из направлений является развитие интеграционных процессов в области взаимодействия государственного и частного капитала, которые отвечают целям и задачам эффективного функционирования, как участников интеграционного взаимодействия, так и региона в целом. Факторами, влияющими на возникновение и развитие интеграционных процессов, являются: дефицитность ресурсов; мотивированная потребность в диверсификации бизнеса; стремление повысить экономическую эффективность хозяйственных субъектов. Развитие интеграционных процессов представляет собой экономическое взаимодействие хозяйствующих субъектов, сопровождаемое их объединением для достижения общих целей и получения синергетического эффекта за счет решения ресурсных, организационных и управленческих проблем. Для получения высоких экономических благ участников интеграционного взаимодействия, нами предложен механизм развития интеграционных процессов в регионе, основанный на трех уровнях взаимодействия органов региональной власти, образовательных учреждений и частных организации. Он позволяет, сформировать единую цепочку управления интеграционными процессами и повысить эффективность реализации их на практике, и избежать недостатков, связанных с формированием интегрированных структур. Интеграционное взаимодействие органов региональной власти с организациями различных сфер деятельности региона и образовательными (научными) организациями является ключевым компонентом инновационной политики России, поскольку, при правильной организации, оно обеспечивает получение более широких преимуществ от капиталовложений в научные исследования, создавая благоприятные предпосылки для устойчивого инновационного развития, и является стратегическим фактором экономического роста региона.

Ключевые слова: интеграционные процессы, регион, интегрированные структуры, механизм развития интеграционных процессов

\title{
The mechanism of development of integration processes in the region
}

\begin{tabular}{lll}
\hline \hline Vladimir M. Bautin & 1 & BMB@mail.ru \\
Marina V. Filatova & 1 & fltvmrn@rambler.ru \\
Kamara Abubakar & 1 & aboubacar2017camara@gmail.com \\
Omesu Jekeledirichukvu Kris & 1 & ekeleliveinrussia@yahoo.com \\
\hline
\end{tabular}

$\mathbf{1}$ Voronezh state university of engineering technologies, Revolution Av., 19 Voronezh, 394066, Russia

Summary. In the context of the weakening economic development of the region, it is necessary to find new ways to increase the efficiency of interaction between the economic structures of the region. One of the areas is the development of integration processes in the field of cooperation between the public and private capital to meet the goals and objectives of the effective functioning of both the participants of integration interaction, as well as the region as a whole. Factors that influence the emergence and development of integration processes, are a scarce resource; motivated by the need to diversify the business; the desire to improve the economic efficiency of business entities. Development grace-integral process is economic interaction managing subjects, followed by combining them to achieve common objectives and obtain the synergistic effect due to a number of resource solutions, organizational and administrative problems. To obtain high economic benefits of integration interaction of the participants, we have proposed a mechanism for the development of integration processes in the region, based on three levels of interaction between regional authorities, educational institutions and private organizations. It allows forming a single chain integration and process management to increase the effectiveness of their implementation in practice, and to avoid the disadvantages associated with the formation of the integrated structures. Integration cooperation of regional authorities with organizations of various spheres of activity of the region and education (research) organizations is a key component of the new Russian innovation policy because, if done right, it provides broader benefits from investments in research and development, creating favorable conditions for sustainable innovation development and is a strategic factor in the economic growth of the region.

Keywords: integration process, region, integrated structure, mechanism of development of integration processes

Для цитирования

Баутин В. М., Филатова М. В., Камара Абубакар, Омесу Экеледиричукву Крис Механизм развития интеграционных процессов в регионе // Вестник ВГУИТ. 2017. № 2. С. 225-230. doi:10.20914/23101202-2017-2-225-230
For citation

Bautin V. M., Filatova M. V., Kamara Abubakar, Omesu Jekeledirichukvu Kris The mechanism of development of integration processes in the region. Vestnik VGUIT [Proceedings of VSUET]. 2017. no. 2. pp. 225-230. (in Russian). doi:10.20914/2310-1202-2017-2-225-230 


\section{Введение}

Внешнеэкономическая политика государств, санкции против России и экономический кризис диктуют стране новый путь развития. Переход от сырьевой экономики к инновационной позволит выйти на новый виток формирования эффективной экономики страны. Согласно мнению В.В. Путина «инновационное развитие - это сфера ответственности всех без исключения министерств и ведомств, региональных властей, бизнеса, научного и экспертного сообщества». По нашему мнению, инновационному развитию страны будут способствовать интеграционные процессы в области взаимодействия государственного и частного капитала, которые отвечают целям и задачам эффективного функционирования и развития их участников, и позволяют получить синергетический эффект за счет решения ресурсных, организационных и управленческих проблем [2].

Под интеграционным процессом следует понимать процесс объединения организационных и/или финансовых ресурсов юридических лиц, имеющих одинаковые цели, в форме интеграционного объединения, которое может быть создано как на договорной основе, так и в результате установления отношений экономической зависимости и/или контроля, в случаях, установленных законодательством или мерами государственного регулирования $[1,9]$.

Массовое развитие интегрированных процессов с участием предприятий пищевой промышленности в отечественной экономике отмечалось в начале 70-х годов прошлого века. В настоящее время процессы интеграции продолжают характеризоваться высокой динамикой, о чем свидетельствует уровень инвестиций в создание и развитие интегрированных формирований. В последние годы динамика инвестиций в основной капитал агропромышленных формирований, например, холдингового типа превышала аналогичный показатель в пищевой промышленности и в экономике в целом [3].

Если рассматривать интеграционные процессы в инновационной сфере, то сегодня в России насчитывается 78 действующих индустриальных парков. Это 7 млн квадратных метров производственных площадей и почти 100 тыс. рабочих мест. За 2015 год в индустриальных парках выпущено продукции на 480 млрд рублей, при этом налоговые поступления в бюджеты всех уровней составили свыше 60 млрд рублей. Инфраструктура индустриальных парков привлекает и зарубежных инвесторов - это свыше 200 иностранных компаний из 25 стран, которые уже разместили свои мощности в России. Об этом сообщил министр промышленности и торговли Российской Федерации Д.В. Мантуров на заседании правительства РФ 24 февраля 2016 года [4].
Д.В. Мантуров отметил, что, помимо индустриальных парков, развиваются и промышленные технопарки, которые осваивают производство новых видов продукции, ориентированной на импортозамещение и наращивание экспортного потенциала. Сегодня в России действуют 16 таких площадок, на территории которых расположены 930 компаний, работающих в высокотехнологичных секторах промышленности, таких как машиностроение, приборостроение, электроника, лазерные технологии, химическая и медицинская промышленность, биотехнологии и новые материалы.

По данным Минпромторга, в настоящее время индустриальные и промышленные технопарки представлены в 47 субъектах Федерации, но даже в сегодняшней непростой экономической ситуации практически все регионы заявляют о намерениях создать новые промышленные зоны. Например, планируется открытие семи площадок в Дальневосточном федеральном округе и четырех - в Республике Крым и Севастополе [4].

Следует отметить, что на территории Воронежской области действует 9 кластеров: кластер производителей нефтегазового и химического оборудования, радиоэлектронный кластер, мебельный кластер, кластер электромеханики, IT-кластер, кластер авиастроения, транспортнологистический кластер, кластер строительных материалов и технологий, мясное скотоводство. Также на территории региона идет активное взаимодействие муниципалитета и частного сектора, в виде муниципально-частного партнерства. Сегодня в рамках этого направления интеграционных процессов осуществляется строительство дошкольных учреждений в областном центре и районах Воронежской области, что позволило сократить очередность в детские сады почти в два с половиной раза, также реализуется реконструкция очистных сооружений в Новой Усмани. Воронежская область стала «пилотным» регионом, где была реализована схема передачи муниципального имущества инвестору по договору концессии, при которой ООО «РВК-Воронеж» реализовало инвестпрограмму объемом финансирования 2 млрд рублей [5].

Процессы, происходившие в экономике региона, исчерпали свой потенциал. Поэтому, несмотря на определённые положительные тенденции, достижение цели обеспечения устойчивой положительной динамики показателей социально-экономического развития региона невозможно без проведения активного вмешательства органов государственной власти [7].

\section{Основная часть}

В настоящее время перспективным направлением развития интеграционных процессов в регионе является вовлечение в их состав предприятий различных сфер деятельности, 
в том числе образовательных и научноисследовательских учреждений. В связи с этим актуальным является обобщение эмпирического материала и разработка эффективных теоретикометодических методов к управлению интеграционными процессами, раскрывающих характер и содержание взаимодействия между участниками объединений на условиях стратегической целесообразности и согласования экономических интересов [1, 3].

Основными преимуществами интеграционных процессов на уровне региона отображены на рисунке 1.

Несмотря на очевидную перспективность и целесообразность формирования интегрированных структур в регионе, этот процесс имеет и ряд недостатков: возникновение монопольных образований, ориентация на достижение целей организаций, инициирующих формирование интегрированных структур и централизация управления [6].

Нами был разработан механизм развития интеграционных процессов в регионе, который позволяет избежать перечисленных выше недостатков, сформировать единую цепочку управления интеграционными процессами и повысить эффективность реализации их на практике.

Представленный механизм на рисунке 2 основывается на трех уровнях взаимодействия органов региональной власти, образовательных учреждений и частных организаций.
Каждый из представленных уровней берет на себя ряд обязательств с целью повышения эффективности и результативности интеграционных связей. Так, деятельность органов региональной власти представлена организационно-административной и нормативно правовой деятельностью, а именно разработка законов и подзаконных актов, целевых программ, проработка государственных заказов, выявление приоритетов развития для конкретного региона, организация работы центров развития стратегических приоритетов и внедрения в процесс принятия решений на региональном уровне нововведений.

Организации различных сфер деятельности региона должны направлять свою деятельность на учет внутренних и внешних факторов. Внутренняя готовность организации к изменениям в структуре работы основывается на готовности сотрудников организации к новым методам управления и к взаимодействию с другими организациями и принятия их структуры управления. Необходимо прибегнуть к новой системе планирования и контроля, которая будет уместна и к другим участникам взаимодействия. Грамотно определить свои технические возможности совместной деятельности и представить объективный экономический механизм получения синергетического эффекта интеграционных связей.

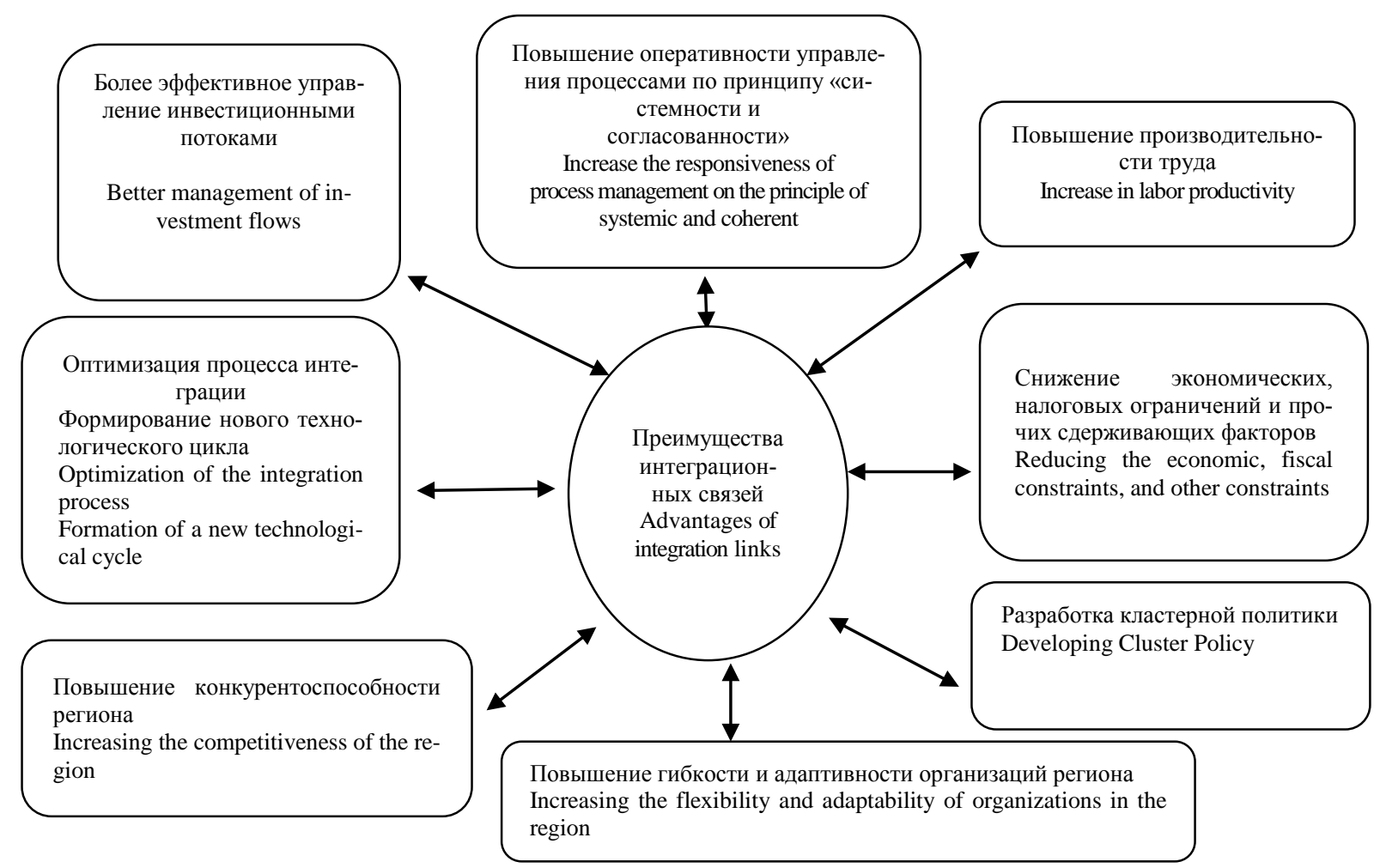

Рисунок 1. Преимущества от использования интеграционных связей в регионе

Figure 1. Advantages of integration ties in the region 


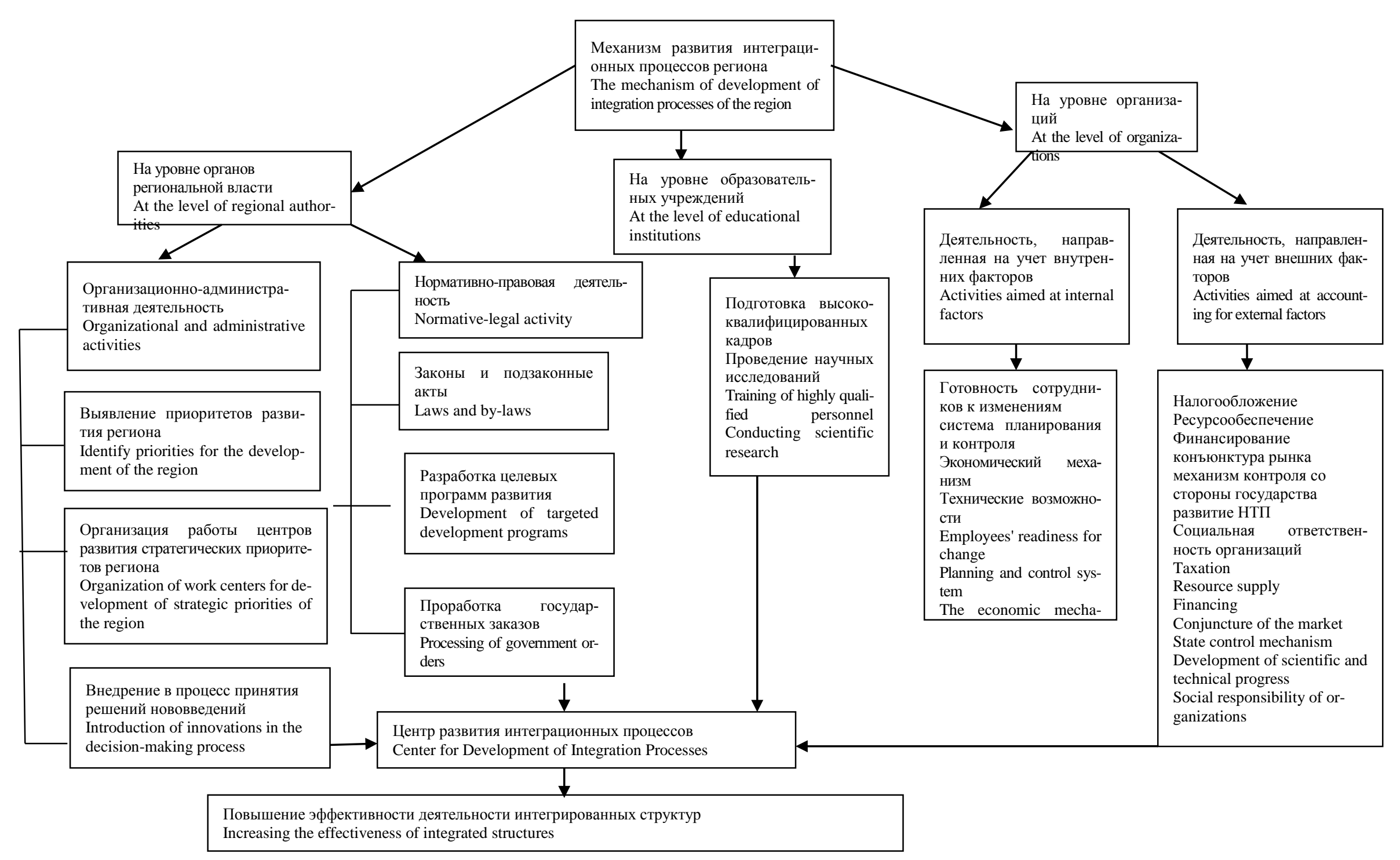

Рисунок 2. Три уровня взаимодействия органов региональной власти, образовательных учреждений и частных организаций

Figure 2. Three levels of interaction of regional authorities, educational institutions and private organizations 
Внешние факторы представлены отслеживанием таких показателей, как объемы финансирования (субсидий), налогообложения, ресурсообеспечения на становление приоритетных направлений развития региона, механизм контроля со стороны органов региональной власти, развития инноваций в интересующей области, а также анализируется социальная ответственность организаций, которые желают вступить и интеграционные связи.

На уровне образовательных учреждений решаются вопросы о повышении образовательного и квалификационного уровня кадров как организаций, так органов государственной власти. Образовательные учреждения также должны проводить научные исследования приоритетных направлений деятельности региона.

Для объединения полученной информации необходимо создание центра развития интеграционных процессов, который будет заниматься объединение организаций по приоритетным направлениям развития региона, что позволит повысить уровень отраслевых и межотраслевых связей, интеграционных и кооперационных процессов между организациями региона, других

\section{ЛИТЕРАТУРА}

1 Баутин В. М., Филатова М. В. Преимущества экономического взаимодействия в форме интегрированных структур // Финансы. Экономика. Стратегия. 2013. № 10. С. 26-29.

2 Сироткина Н. В., Филатова М. В., Поляков А. В. Интеграционные процессы в эпоху системных инноваций: новое в теории и практике // Вестник СевероОсетинского государственного университета имени Коста Левановича Хетагурова. 2015. № 3. С. 254-259.

3 Воробьев А. А., Сироткина Н. В. Формирование горизонта роста потенциала развития интеграционных процессов инновационной деятельности в регионе // Знание. 2016. № 2-2 (31). С. 14-17.

4 Мантуров Д.В. О развитии индустриальных парков и технопарков Сайт Правительство России. URL: http://government.ru/news/21920/\#man

5 Брякина А. В., Сироткина Н. В. Основные направления развития научно-производственных кластеров в регионе // Сборник научных трудов по материалам Международной научно-практической конференции: Современные тенденции в науке и образовании Москва: АрКонсалт., 2014. С. 95-97.

6 Воробьев А. А. Характеристика методов развития интеграционных процессов мезо-уровня при активном участии субъектов инновационной деятельности // Международная научно-практическая конференция Современные технологии в мировом научном пространстве. Казань: Аэтерна, 2016. 134-136 с.

7 Горюнова Л. А., Полухина О. А. Механизм интеграционного взаимодействия институциональных единиц регионально-социально-экономического комплекса // Экономика и предпринимательство. 2016. № 12-1. С. 857-860. регионов РФ, стран СНГ и дальнего зарубежья, вследствие чего повысится эффективность деятельности интегрированных структур.

Интеграционное взаимодействие органов региональной власти с организациями различных сфер деятельности региона и образовательными (научными) организациями является ключевым компонентом инновационной политики России, поскольку, при правильной организации, оно обеспечивает получение более широких преимуществ от капиталовложений в научные исследования, создавая благоприятные предпосылки для устойчивого инновационного развития, являющего стратегическим фактором экономического роста.

\section{Заключение}

На основании вышеизложенного можно сделать вывод о перспективности механизма развития интеграционных процессов в регионе, что связано с интересами участников интеграционных процессов и в целом для региона. Представленный механизм затрагивает такие сферы, как образование, бизнес государственной власти и их тандем в работе будет способствовать достижению стратегических целей региона.

8 Yao J., Deng Z. Dynamic resource integration optimisation of global distributed manufacturing: an embeddedness-interaction perspective //International Journal of Production Research. 2016. T. 54. №. 23. C. 7143-7157.

9 Wei T., Clegg J. Strategic resources: a missing role in understanding integration speed in international acquisition //Thunderbird International Business Review. 2017.

10 Eslami M. H., Lakemond N. Internal Integration in Complex Collaborative Product Development Projects //International Journal of Innovation Management. 2016. T. 20. №. 01. C. 1650008.

11 Kiryushin V.A. Features of small innovative enterprises development in the conditions of krasnoyarsk region // Russian Journal of Agricultural and Socio-Economic Sciences. 2015. T. 44. № 8. C. 3-10.

\section{REFERENCES}

1 Bautin V. M., Filatova M. V. The advantages of economic cooperation in the form of integrated structures. Finansy. Ekonomika. Strategiya [Finance. Economy. Strategy]. 2013. no. 10. pp. 26-29. (in Russian).

2 Sirotkina N. V., Filatova M. V., Polyakov A. $\mathrm{V}$. Integration processes in the era of systemic innovation: new developments in theory and practice. Vestnik Severo-Osetinskogo gosudarstvennogo universiteta imeni Kosta Levanovicha Khetagurova [Proceedings of North Ossetian state University named after Costa Levanovich Khetagurov]. 2015. no. 3. pp. 254-259. (in Russian).

3 Vorob'ev A. A., Sirotkina N. V. The formation of the horizon is the growth of the potential development of integration processes of innovative activity in the region. Znanie [Knowledge]. 2016. no. 2-2 (31). pp. 14-17. (in Russian). 
4 Manturov D.V. About the development in governmental parks and technology parks. Site of the Russian Government in 2016. Available at: http://government.ru/news/21920/\#man (in Russian).

5 Bryakina A. V., Sirotkina N. V. Osnovnye napravleniya razvitiya nauchno-proizvodstvennykh klasterov v regione Sbornik nauchnykh trudov po materialam Mezhdunarodnoi nauchno-prakticheskoi konferentsii: Sovremennye tendentsii $\mathrm{v}$ nauke i obrazovanii [The main directions of development of scientific and production clusters in the region, Collection of scientific works on materials of the International scientific-practical conference: Modern trends in science and education]. Moscow. ArKonsalt. 2014. pp. 95-97. (in Russian).

6 Vorob'ev A. A. Kharakteristika metodov razvitiya integratsionnykh protsessov mezo-urovnya pri aktivnom uchastii sub"ektov innovatsionnoi deyatel'nosti Mezhdunarodnaya nauchno-prakticheskaya konferentsiya Sovremennye tekhnologii v mirovom nauchnom prostranstve [Characteristics of the methods of development of integration processes in the meso-level with the active participation of the subjects of innovative activities of the international scientific and

\section{СВЕДЕНИЯ ОБ АВТОРАХ}

Василий М. Баутин д. э. н., профессор, Воронежский государственный университет инженерных технологий, пр-т Революции, 19, г. Воронеж, 394066, Россия, BMB@mail.ru

Марина В. Филатова к. э. н., доцент, Воронежский государственный университет инженерных технологий, пр-т Революции, 19, г. Воронеж, 394066, Россия, fltvmrn@rambler.ru

Камара Абубакар магистр, Воронежский государственный университет инженерных технологий, пр-т Революции, 19, г. Воронеж, 394066, Россия, aboubacar2017camara@gmail.com

Омесу Экеледиричукву Крис магистр, Воронежский государственный университет инженерных технологий, пр-т Революции, 19, г. Воронеж, 394066, Россия, ekeleliveinrussia@yahoo.com

\section{КРИТЕРИЙ АВТОРСТВА}

Василий М. Баутин консультация в ходе исследования Марина В. Филатова написала рукопись, корректировала её до подачи в редакцию

Камара Абубакар обзор литературных источников по исследуемой проблеме

Омесу Экеледиричукву Крис несёт ответственность за плагиат

\section{КОНФЛИКТ ИНТЕРЕСОВ}

Авторы заявляют об отсутствии конфликта интересов.

ПОСТУПИЛА 01.08.2017

ПРИНЯТА В ПЕЧАТЬ 20.08.2017 practical conference Modern technology in the world scientific space]. Kazan. Aeterna. 2016. pp. 134-136. (in Russian).

7 Goryunova L. A., Polukhina O. A. The mechanism of integration interaction institutional units of the regional socio-economic complex. Ekonomika $i$ predprinimatel'stvo [Economics and entrepreneurship]. 2016. no. 12-1. pp. 857-860. (in Russian).

8 Yao J., Deng Z. Dynamic resource integration optimisation of global distributed manufacturing: an embeddedness-interaction perspective //International Journal of Production Research. 2016. vol. 54. no. 23. pp. 7143-7157.

9 Wei T., Clegg J. Strategic resources: a missing role in understanding integration speed in international acquisition. Thunderbird International Business Review. 2017.

10 Eslami M. H., Lakemond N. Internal Integration in Complex Collaborative Product Development Projects. International Journal of Innovation Management. 2016. vol. 20. no. 01. pp. 1650008.

11 Kiryushin V.A. Features of small innovative enterprises development in the conditions of krasnoyarsk region. Russian Journal of Agricultural and Socio-Economic Sciences. 2015. vol. 44. no. 8. pp. 3-10. (in Russian).

\section{INFORMATION ABOUT AUTHORS}

Vladimir M. Bautin степень (без сокращений), должность, Voronezh state university of engineering technologies, Revolution Av., 19 Voronezh, 394066, Russia, BMB@mail.ru

Marina V. Filatova candidate of conomical sciences, assistant professor, Voronezh state university of engineering technologies, Revolution Av., 19 Voronezh, 394066, Russia, fltvmrn@rambler.ru

Kamara Abubakar master student, Voronezh state university of engineering technologies, Revolution Av., 19 Voronezh, 394066, Russia, aboubacar2017camara@gmail.com

Omesu Jekeledirichukvu Kris master student, Voronezh state university of engineering technologies, Revolution Av., 19 Voronezh, 394066, Russia, ekeleliveinrussia@yahoo.com

\section{CONTRIBUTION}

Vladimir M. Bautin consultation during the study Marina V. Filatova wrote the manuscript, correct it before filing in editing

Kamara Abubakar review of the literature on an investigated problem

Omesu Jekeledirichukvu Kris is responsible for plagiarism

\section{CONFLICT OF INTEREST}

The authors declare no conflict of interest.

RECEIVED 1.8.2017

ACCEPTED 8.20.2017 